\title{
AUTOMATION OF MAGNETIC PARTICLE INSPECTION MACHINE FOR PERFORMANCE OPTIMIZATION
}

\author{
Param Tadamalle $^{1}$, Shubham Thopate ${ }^{1}$, Pushkaraj Tatiya ${ }^{1}$, Himanshu Ranjan ${ }^{1}$, V. N. Kapatkar ${ }^{2}$, \\ Dinesh Doundkar ${ }^{3}$, Rahul Shiraskar ${ }^{4}$ \\ Scholars, Mechanical Engineering, Sinhgad College of Engineering, Pune, India ${ }^{1}$ \\ Professor, Mechanical Engineering, Sinhgad College of Engineering, Pune, India ${ }^{2}$ \\ Asso. Vice President, Processing, Bharat forge Ltd., Mundwa, Pune, India ${ }^{3}$ \\ Sr. Manager, Processing, Bharat forge Ltd., Mundwa, Pune, India ${ }^{4}$
}

\begin{abstract}
Magnetic Particle Inspection is one of the most commonly used non-destructive testing method for detecting surface and limited sub-surface indications in ferromagnetic materials. When a component undergoes forging process, due to excessive stresses while manufacturing there occurs a change in its grain structure which may lead to cracks on it. The aim of this project is to retrofit manually operated Magnetic Particle Inspection (MPI) machine for performance optimization. To cope up with the problem associated with existing machine the changes that have been incorporated include design of automatic coil movement with continuous solution spraying and maintaining solution concentration, current and voltage monitoring to ensure appropriate amount of magnetic field induced. The MPI machine is retrofitted with sensors, actuators and PLC. These sensors have been integrated with a PLC to monitor the input and make decisions based on the custom program to achieve required output. The designed components are analyzed for bearing expected load. Incorporation of higher levels of automation and digitization has led to reduced human intervention and work time. The present project work is helpful in industries like Forging Shops, Aircraft Overhaul Stations, Heat treatment Plants.
\end{abstract}

Keywords: MPI, PLC, Sensors and actuators, CFD Analysis

\section{INTRODUCTION}

The process of having a machine follow a predetermined sequence of operation with little or no human labor, using special equipment and devices that perform and control manufacturing processes is known as automation. The earliest known use of magnetism to inspect an object took place as early as 1868. In the early 1930's, magnetic particle inspection was quickly replacing the oil-and-whiting method to inspect steam engine boilers, wheels, axles, and tracks. Today, the MPI inspection method is used extensively to check for flaws in a large variety of manufactured materials and components. MPI is used to highlight defects that are not necessarily visible to the human eye. The process involves magnetization of the components and simultaneous spraying of Ferro-magnetic particles. This method consists of various steps which are done manually in the industry affecting the efficiency of the procedure. Automation is the key to modernization as it is a way to increase efficiency and to improve productivity. Automation has revolutionized the areas in which it has been introduced and almost every aspect of modern life has been affected by it. The fundamental constituents of any automated process are a power source, a feedback control mechanism, and coding. The automation tools include relays, contactor logic and Programming logic controllers.

This paper gives an overview of currently available and emerging optical technologies for sensing and communication applications and reviews their possible application in the context of the IoT for realizing smart systems and infrastructures.[1] In this paper, distance sensitivity properties inherent in many sensor-actuator network-based control systems are exploited to establish conditions under which information within a bounded locality of each controller closely approximates optimal control based on knowledge of system-wide state information [2] this paper presents the concept of smart industrial control services (SICS) as a new type of a PLC. As a distributed service-oriented control system in an IP network, a SICS controller can replace the traditional PLC for applications with uncritical timing in terms of Industry 4.0. The SICS are programmed as usual in industry, according to the standard IEC 61131-3, and run in a SICS runtime on a server or in a cloud. The term Smart Service is introduced and the uses of SICS as a smart service, including a clearing system for the creation of new business models based on control as a service [3]. 


\section{International Advanced Research Journal in Science, Engineering and Technology}

Vol. 8, Issue 6, June 2021

\section{DOI: $10.17148 /$ IARJSET.2021.8602}

In deals with 2 cases to derive relationship equation between calculated value and predicted value of TSS. In case 1 , light was transmitted through the sample when the angle between light source and photodiode was $180^{\circ}$, and for case 2 , light was scattered by small particles in the sample when the angle between light source and photodiode was $90^{\circ}$. An algorithm equation was developed and used to determine the relationship between measured TSS and predicted TSS [4]. Performance evaluation of the development of the instrumentation, communications and control systems of a two-tank process by using low-cost hardware and open source software. The hardware used for automating this process consists of embedded platforms (Arduino and Raspberry Pi) integrated into programmable logic controllers (PLCs), which are connected to a supervisory control and data acquisition (SCADA) system implemented with an open source Industrial Internet of Things (IIoT) platform. The main purpose of the proposed approach is to evaluate low-cost automation solutions (hardware and software) within the framework of modern industry requirements in order to determine whether these technologies could be enabling factors of IIoT [5]. The machine and plant automation model-driven programming of Programmable Logic Controller (PLC) software is becoming an alternative to the advanced programming. The paper presents the results of an evaluation of a newly developed Multi Agent System (MAS) approach for PLCs. A new alternative for old programming automation process using PLC. Selection of most suitable PLC for the machine, sensors and actuators used in the industry [6].

An automatic picking and converting line to automatically transport work bin in spacecraft assembly warehouse was designed. A three level control system structure was designed i.e. computers, PLC and actuating mechanism. The automatic picking and conveying line control software was developed based on the basic class library MFC software. The SIEMENS S7-315 PN/DP PLC was used to control the actuators in the pick and place robot, conveyer system and sensors. The knowledge and application of automatic conveyor belt system and use of automatic picking system with the help of sensors and actuator integrated with PLC The knowledge and application of automatic conveyor belt system and use of automatic picking system with the help of sensors and actuator integrated with PLC [7]. The creation of a digital twin for an experimental assembly system based on a belt conveyor system and an automatized line for quality production check was done in this research paper. The main task was parts identification and inspection, with the synchronization of all data to a digital twin model. The use of Conveyer Belt system to move the product and use of different sensors to check the products [8]. This paper deals with retrofitting manually operated Magnetic Particle Inspection (MPI) machine for performance optimization by designing of mechanism for automatic movement of the magnetizing coil, automatic system for mixture of fluorescent magnetic powder and water and to acquire real time data from sensors and operate the actuators accordingly.

\section{DESIGN AND MODELLING OF MPI MACHINE}

This paper presents the design of an automatic solution preparation system and automatic coil movement system using PLC. This design makes use of the PLC and HMI to control the process. In this design, the overall objectives were met. By keeping track of the solution concentration, the PLC is able to control the water flow and powder flow. Using the data from the sensors the PLC controls the movement of the coil. Design and modeling of components are presented in detail in the following sections.

\section{A. Solution preparation}

The basic concept to design an automating solution preparation system (Fig. 1) was to make the process more reliable and fast. The main concern was to maintain the concentration of the solution and also to make sure that water and the powder are mixed proportionally to keep the concentration in check. To develop this system, some components were designed and some were taken as OEM's. The hopper was designed to store the powder in a cool ventilated place. As the powder is hygroscopic in nature, it had to be kept away from moisture. The hopper was designed taking into consideration the required capacity of $2 \mathrm{kgs}$. While designing the pressure generation in the hopper was also considered to obtain constant flow as the powder was going to flow freely under the force of gravity. To make the hopper lightweight and durable, polyethylene was chosen as the material of the hopper. A wafer style butterfly valve was selected as the powder flow was unidirectional and it shuts off the very tightly. As the powder size is very small it was important that the valve shuts off tightly. The valve size of $1 / 2$ " was selected by calculating the required mass flow rate of the powder analytically. A 1" normally closed electric solenoid valve was selected to regulate the flow rate of water. As the solenoid valves has a very low operating time of 5-10 milliseconds, it suited well for our requirement as the regulation of on and off is required for small 15 intervals of time. The solenoid valve will be operated by the inputs from the concentration sensor which measures the concentration of the solution. If the concentration dips in the solution, the PLC by the input from the concentration sensor will open and close the valve for the required proportion of the water. The water and powder is mixed inside the solution tank. When water and powder falls into the tank, a stirrer mixes them for $10-15$ min so that powder is completely dispersed into the water. 


\section{International Advanced Research Journal in Science, Engineering and Technology}

Vol. 8, Issue 6, June 2021

\section{DOI: $10.17148 / I A R J S E T .2021 .8602$}

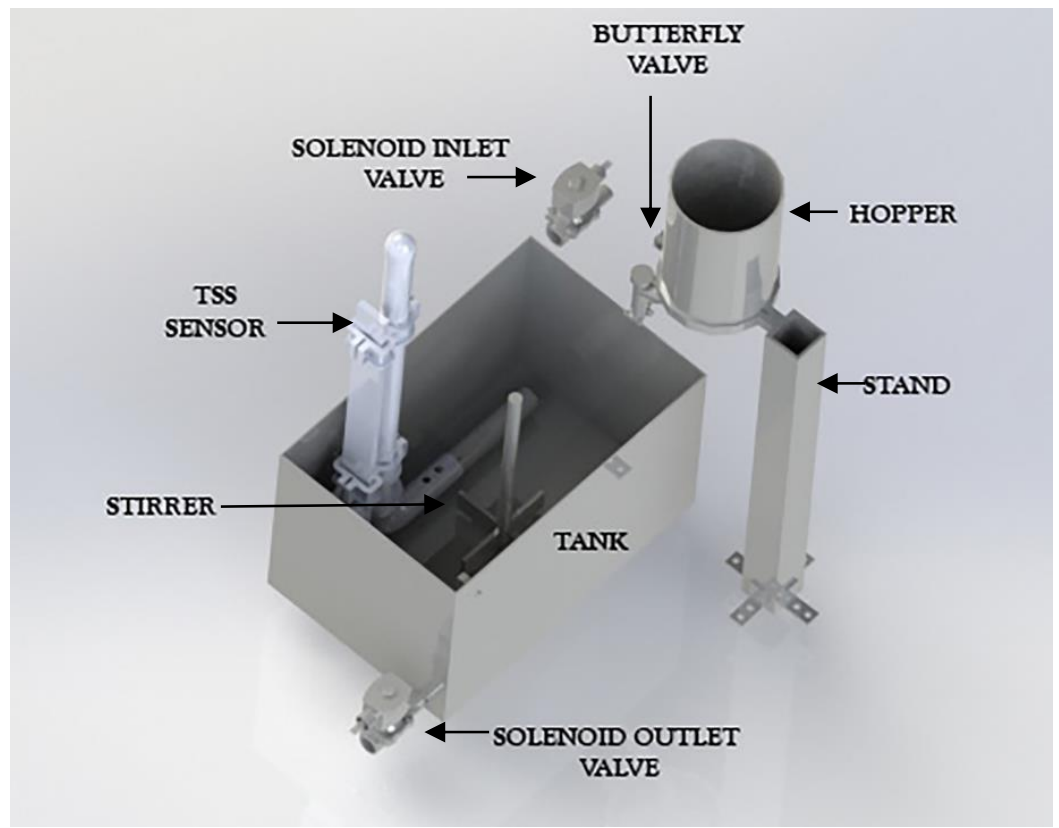

Fig. 1 Solution preparation tank

\section{B. Coil movement}

The following sections discuss the design of automatic coil movement, automatic magnetic shot, and automatic solution spraying. To make the coil movement automatic following components were incorporated as shown in Fig. 2: 1. Magnetizing Coil 2. Chain and sprocket 3. Induction motor 4. Proximity sensors 5. Solution Sprayers 6. Spiral hoses. Magnetizing coil magnetizes the axle beams placed on the support. The coil is an OEM component of the machine. The modification has been done on the coil to make it fully automatic. The supporting members are added to the coils for the mounting of the solution sprayers. The supporting members should be non-conductive, corrosion-resistant, durable, and chemical resistant. Taking into consideration these parameters UPVC (unplasticized polyvinyl chloride) material was selected for the supporting members. A chain drive was chosen due to its characteristics of both belt and gear drive. As the bed length was long and available space was less, chain drive was a suitable option and entire design of chain has been carried out by taking factor of safety for chain drive as 6.61, it satisfies the required standards of our design. So the chain 140-1SS of pitch $44.45 \mathrm{~mm}$ which has extra corrosion resistant application and sprocket ISO 28B-1 of type A was selected.

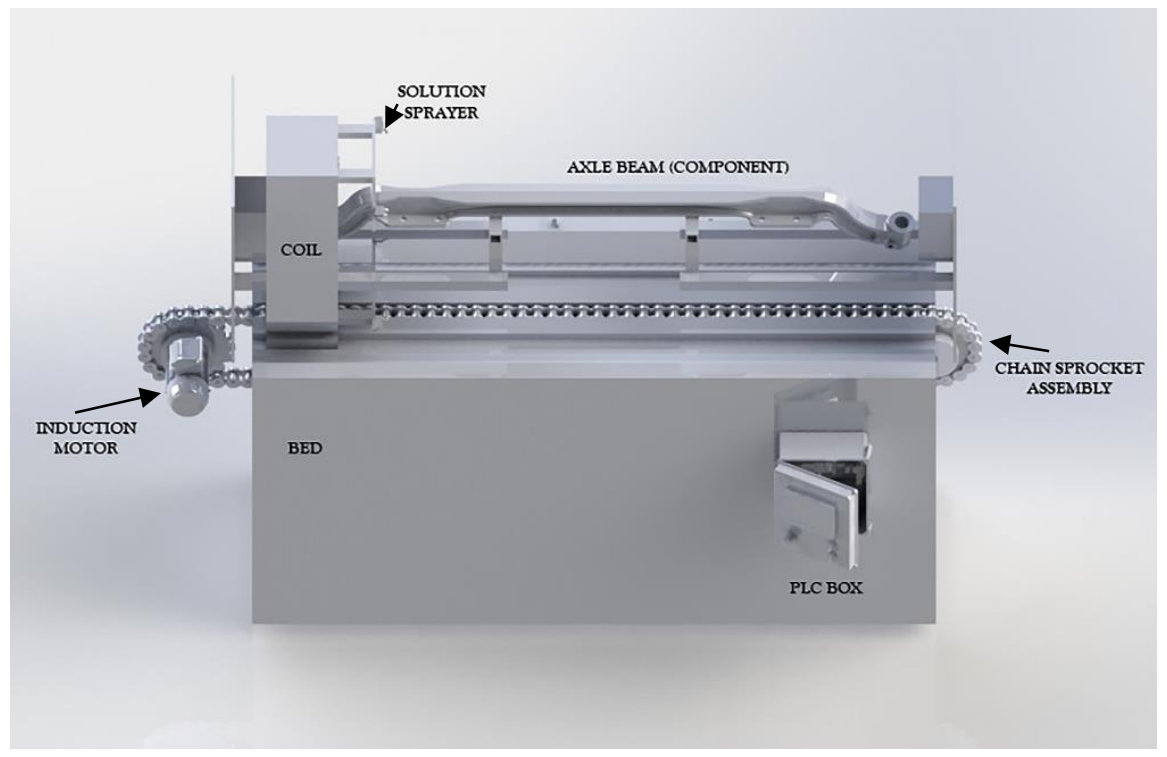

Fig. 2 Automatic coil assembly 


\section{International Advanced Research Journal in Science, Engineering and Technology}

Vol. 8, Issue 6, June 2021

\section{DOI: $10.17148 /$ IARJSET.2021.8602}

The induction motor in the application has been integrated with the PLC for controlling the rpm and polarity of the motor. The addition of PLC in the existing system for control and automation of induction motor leads to accuracy which is higher than the normal traditional voltage frequency (V/f) control mechanism. Crompton 3 Phase 1HP 2 Pole Foot Mounted Induction Motor IE3 was chosen for the movement of coil because of the following features Sturdy construction, Rust resistance, Incredible strength, Easy handling. Smooth execution. High tolerance and robust construction. The solution sprayers are mounted on the supporting member of the coil with M6x1 bolts and can be replaced easily after any malfunction. A market study was done to select the most appropriate sprayer. The hose is used to connect the sprayer with the outlet of the solution tank. As the sprayer is integrated with the coil which moves to and fro on the bed to magnetize the axle beam, a hose that would stretch while the coil is away from the home position was needed. And also would attain its original shape when it is at back at home position. This parameter was satisfied by the spiral hoses which are durable, stretchable up to 5-10m which was more than sufficient for the application. Thus the spiral hose was selected to connect the main pipe of the solution to the sprayer.

\section{Selection of sensor}

In automation, sensors play a very important role as they provide information to the control system about the process, if there is any change in the specific quantity like change in temperature, pressure, velocity, etc. Ultrasonic sensor are devices that generate or sense ultrasound energy. MPI continuously uses the fluorescent solution for inspection so the tank needs to be filled with the solution all the time as well as concentration should be kept constant. The flow of water is controlled by a solenoid valve which is controlled by PLC. But for PLC to control the valve, it would need continuous information about the water level in the solution tank. A sensor has been placed at the top of the tank facing downwards. The sensor selected is Baumer U300.D50-DPMJ.72N. The sensor has a detecting range of 15-500mm. The sensor also has an IP67 rating which makes it suitable to be directly placed inside the tank. The resolution of the sensor is less than or equal to $0.3 \mathrm{~mm}$. The sensor has a minimum response time of $16 \mathrm{~ms}$ with an accuracy of $0.5 \mathrm{~mm}$.

Digital Suspended Solids Sensor TSS includes solids that can settle, and is the direct measurement of the total solids present in a water body. As such, TSS can be used to calculate sedimentation rates, while turbidity cannot. When in the solution the particle size of the non-soluble particles is greater than 2 microns, a Total Suspended Solids (TSS) sensor is used to detect its concentration. The sensor operates on the principle of single gap light absorption as a means of detecting the presence of suspended solids. The sensors utilize an infrared emitter to minimize color effects and compensate for emitter variations due to temperature by measuring source brightness. The sensors incorporate self-cleaning optics via air or waterjet. The principle of the TSS sensor is based on the combined infrared absorption and scattered light method. The sensor directs a beam of infra-red light into the sample, using an LED emitting at a wavelength of 850nm. The light beam is scattered by particles in the sample, and the scattered light intensity is measured by the sensor's photodetector positioned at 90 degrees to the light beam. 0-200mg/L, 0-5000mg/L, 0- 50000mg/L, a variety of measuring ranges are available, suitable for different working conditions, the measurement accuracy is less than $\pm 5 \%$ of the measured value. As per the product data sheet of the fluorescent magnetic powder Magnaglow MG 2410 SPL the recommended concentration of the powder is $10.75 \mathrm{gm} / \mathrm{L}$. This fluorescent magnetic powder complies with the ASTM standard E1444 which is referred for the standard test procedure of the magnetic particle inspection. As TSS sensor measures the concentration between the ranges of $0-50000 \mathrm{mg} / \mathrm{L}$, it can replace the current test procedure of the concentration measurement.

Proximity Sensor is used as the length of the bed is approximately 98 inches and the coil moves over the bed for magnetizing the axle beam. So for automizing this process the coil movement has to be made automatic and the length that the coil moves has to be monitored continuously. For this purpose, ultrasonic proximity sensors were chosen. The proximity sensors are placed on the bed. 7 proximity sensors are fitted on the edge of the bed. The first sensor is placed at the right corner of the bed which is the starting point for the motion of the coil for giving the shot The sensor selected is Baumer U300.D50-DPMJ.72N. The sensor has a detecting range of $15-500 \mathrm{~mm}$. The resolution of the sensor is less than or equal to $0.3 \mathrm{~mm}$. The sensor has a minimum response time of $16 \mathrm{~ms}$ with an accuracy of $0.5 \mathrm{~mm}$.

\section{IMPLEMENTATION OF PLC FOR PROCESS CONTROL}

A PLC can be hardware-based or software-based PLC. Hardware PLC is mostly composed of hardware components that are controlled by high-level programming language. A software-based PLC is a combination of hardware PLC and PC. Software based PLC can be programmed using a wide range of programming languages and there's better control over the operation performed by PLC. Software based PLC was chosen because the PLC needed to control various applications 


\section{International Advanced Research Journal in Science, Engineering and Technology}

Vol. 8, Issue 6, June 2021

\section{DOI: $10.17148 /$ IARJSET.2021.8602}

simultaneously and quickly. Based on the above condition a PLC was selected. Siemens "SIMATIC ET 200SP" fulfilled all the conditions for the required application. Human Machine Interface (HMI) is a display that provides the process and system information and also facilitates for providing input to PLC. It is an interface or dashboard that connects a person to a machine, system, or device. In this application as the PLC was Siemens "SIMATIC ET 200SP" so based on the requirement and compatibility Siemen's "TP1500 Comfort portrait" with a 7-inch display was chosen.

\section{A. Solution preparation}

The funnel gets input from PLC in response to the input which it gets from the concentration sensor. The concentration sensor checks the concentration of liquid in the tank and sends the signal to PLC, if the concentration is equivalent to the required concentration of the liquid then the sensor sends low input resulting in no change in the position of the butterfly valve which is initially closed. But when the concentration of liquid is not equal to the required concentration then the sensor sends high input to PLC resulting in the opening of the butterfly valve. The PLC compares as well as calculates by how much amount the concentration is changed and according to that the amount of powder to be added is calculated. The flowrate of powder is $11 \mathrm{gm} / \mathrm{s}$ when the valve is opened, according to that PLC determines the time for which it should remain open.

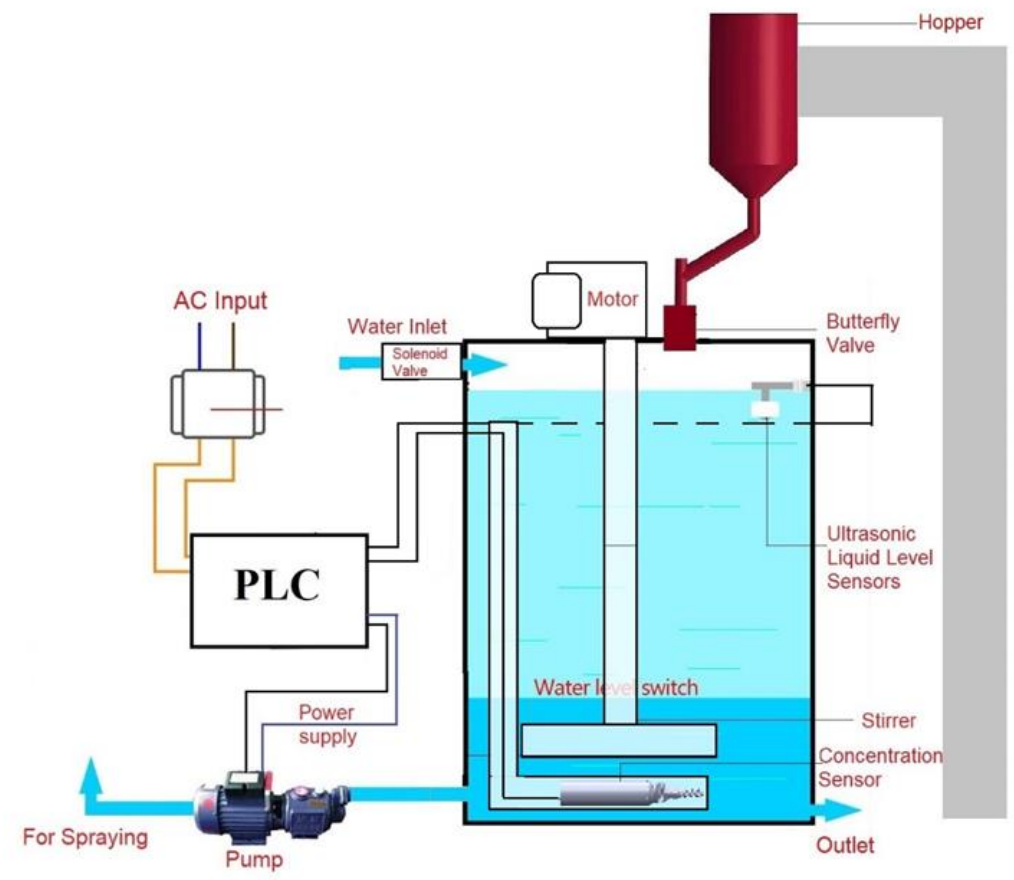

Fig. 3 Solution preparation process control

\section{B. Automatic coil movement and spraying}

The Axle beam is placed at position A. There are 7 proximity sensors on the bed. The axle beam position and length measurement of the axle beam is done by these sensors and they send these data to PLC which is later on processed by the PLC, which then sends signal to the motor to start the movement of coil. The coil moves from position A to B while spraying the magnaflux solution over the axle beam. After spraying the signal goes to PLC and the polarity of motor is changed now the coil will move from position B to A. The length measured by the sensors is compared to a previously stored length of 72 inches. If the length of axle beam is smaller or equivalent to the previously stored length then the coil moves 9 inches covering the maximum length of 18 inches, and gives 4 successive magnetic shots to the beam over a distance 18 inches successively. If the axles beam length is more as compared to the stored length than the coil moves 9 inches and gives 5 successive magnetic shots at a distance of 18 inches. If the coil is at position A then the axle beam is replaced with the fresh one and the cycle repeats 


\section{International Advanced Research Journal in Science, Engineering and Technology}

Vol. 8, Issue 6, June 2021

\section{DOI: $10.17148 /$ IARJSET.2021.8602}

\section{IV.RESULT AND DISCUSSION}

This project work deals with the problem associated with the existing machine, the changes that have been incorporated are maintaining solution concentration, design of automatic coil movement with continuous solution spraying and current and voltage monitoring to ensure an appropriate amount of magnetic field induced. The MPI machine is retrofitted with sensors, actuators, and PLCs. These sensors have been integrated with a PLC to monitor the input and make decisions based on the custom program to achieve the required output. The designed components are analyzed forbearing the expected load. Incorporation of higher levels of automation and digitization has led to reduced human intervention and work time. The automatic solution preparation tank was designed and developed successfully. The solution preparation, for NDT before the project work, was manual. But after this project work, the addition of water and powder for solution preparation is made completely automatic by installing sensors, valves, and PLC. The flow rate was calculated for the butterfly valve it is found to be $11.46 \mathrm{gm} / \mathrm{sec}$ based on this flow rate OEM butterfly valve is selected. An ultrasonic water level sensor is used to monitor the water level. For manually checking the concentration of solution the settling method was used which takes about $30 \mathrm{~min}$ to give the result, however after installing the TSS sensor the time required to check the concentration has been reduced to $2-5 \mathrm{sec}$. The proposed system takes 40 secs to prepare a solution when the tank is empty.

The design and CAD modelling of automatic coil movement with a continuous solution spraying system was developed to reduce human intervention and to reduce the process cycle time. The coil movement and solution spraying were manual but by incorporating a sprocket chain mechanism, Induction motor, proximity sensors, hoses, and necessary attachment the process is made automatic. By analytical calculation chain and sprocket, dimensions were determined. The length of the chain is calculated to be $5756.2 \mathrm{~mm}$ for an average velocity of $506 \mathrm{~mm} / \mathrm{s}$ which has a rated power of $1000 \mathrm{KW}$. For the sprocket PCD chosen is $256 \mathrm{~mm}$. Ultrasonic proximity sensor is chosen to determine the position of the coil for giving a magnetic shot. By automating the process human intervention became zero. The earlier cycle time was 40 secs but after making the process automatic the cycle time is reduced to $21 \mathrm{sec}$. The cycle time for coil movement and solution spraying was reduced by $47.5 \%$.

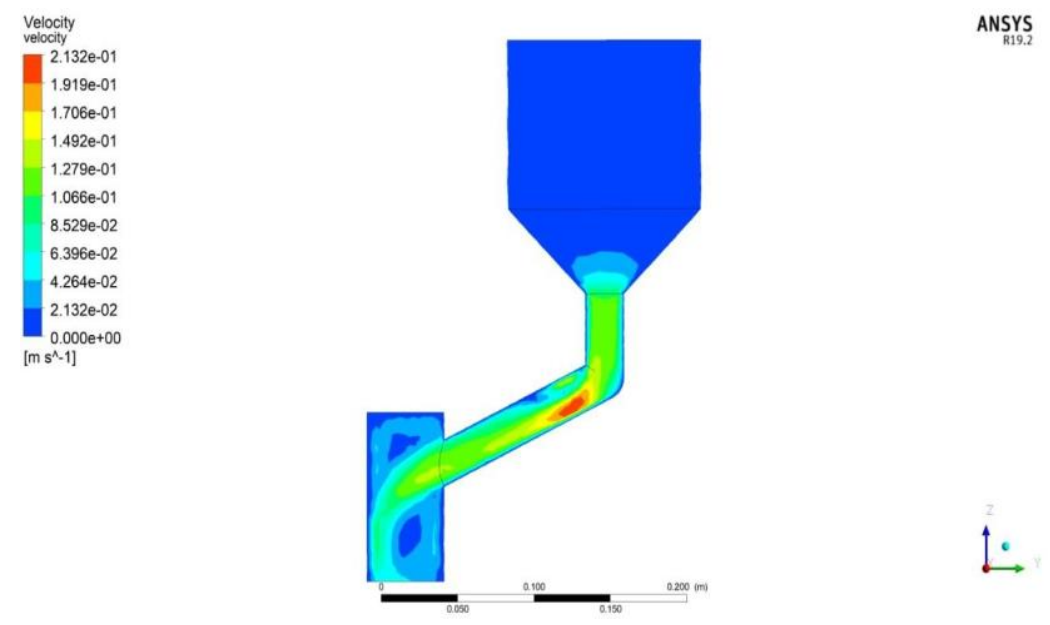

Fig. 4 Velocity distribution of the powder flow

The analytical design of the hopper is done by taking into consideration the various constraints. The system is modelled using CATIA software and meshed using tetrahedral elements in ANSYS. Fluent flow analysis for powder flow under the effect of gravity was done for velocity distribution and pressure distribution in the hopper. The result of velocity distribution is presented in Fig 4. The maximum velocity of $0.2 \mathrm{~m} / \mathrm{s}$ is obtained in the passage tube (after the bend) through which the powder flows from the hopper to the discharge tube this is due to the exertion of powder pressure of the powder stored in the hopper. This indicates the continuous flow of powder in the system in case of open valve condition. The velocity of powder is constant in the vertical pipe connected to the hopper but in the incline position of the tube, it is observed that the velocity of powder is varying. In the discharge tube, the velocity distribution is found to be uneven and wakes were observed above the below the powder flow path. 


\section{International Advanced Research Journal in Science, Engineering and Technology}

Vol. 8, Issue 6, June 2021

DOI: $10.17148 /$ IARJSET.2021.8602

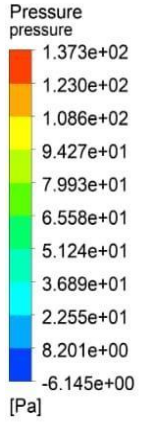

$086 \mathrm{e}+02$

$558 \mathrm{e}+0$

$124 \mathrm{e}+01$

$255 \mathrm{e}+01$

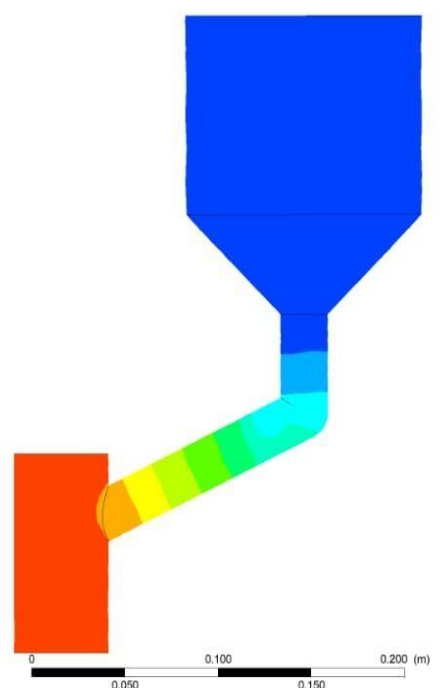

$\underset{\mathrm{R} 19.2}{\operatorname{AnSYS}}$

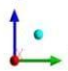

Fig 5 Pressure Distribution of stored powder in Hopper

Fig 5 shows the pressure distribution in the hopper when the powder is stored. The diagram reveals that the maximum pressure of $137.3 \mathrm{~Pa}$ is in the discharge tube. Itis also observed that the portion connecting the discharge tube to the hopper is subjected to maximum fluctuation in pressure from 6.45 $\mathrm{Pa}$ to $123 \mathrm{~Pa}$ this is due to inclination and sudden bend in the pipe and also because of pressure exerted by the powder present in the hopper. From the analysis it was found that the maximum velocity attained by powder under the effect of gravity was $0.2 \mathrm{~m} / \mathrm{s}$ in the connecting tube and the maximum pressure was of $137.3 \mathrm{~Pa}$ in the discharge of the hopper.

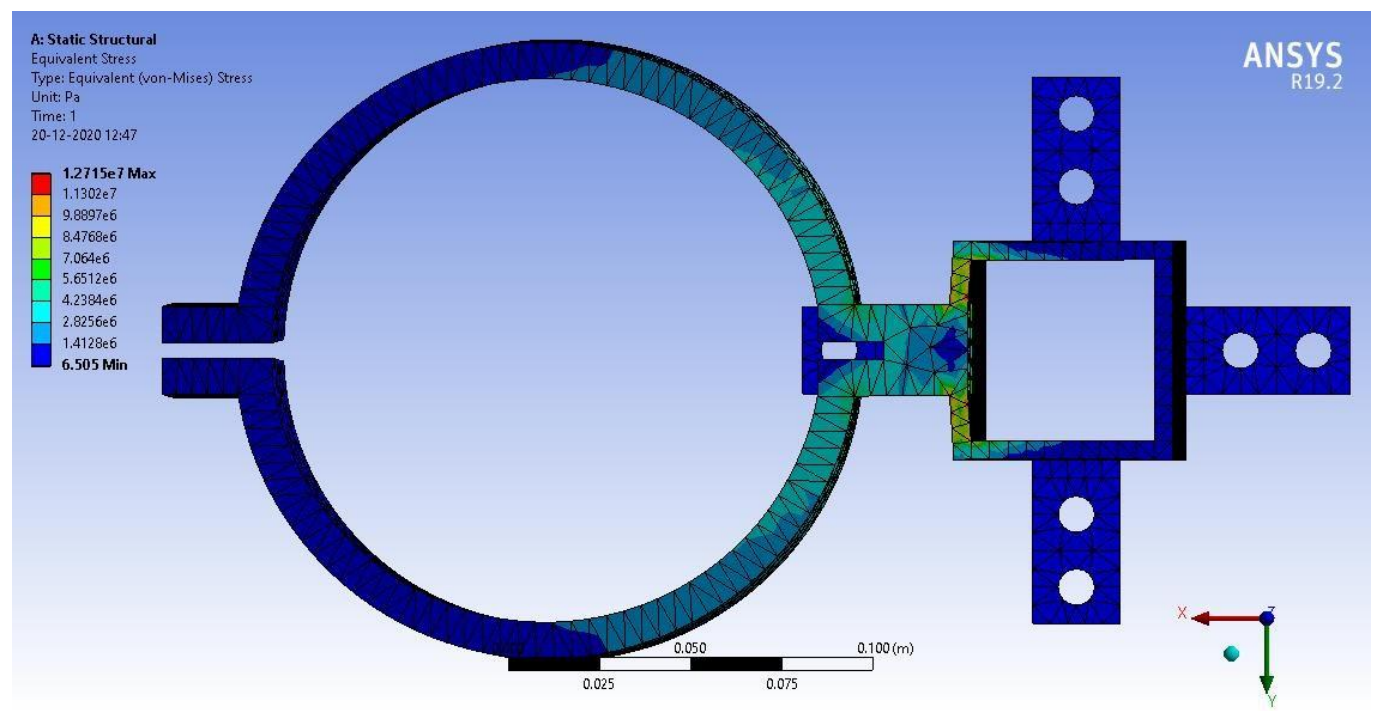

Fig 6 Equivalent stress distribution in Stand

The stand is designed taking into consideration the adjoining space, weight of hopper (4-5 $\mathrm{kg}$ ) and shape of the hopper. The static structural analysis for predicting the stress and deformation was performed on the stand. The material selected was 304L stainless steel. The stress distribution in the stand is shown in Fig 6. It depicts that the stress level in the stand is maximum at the joint between ring and column which is $12.7 \mathrm{pa}$. From the figure it can also be seen that the half portion of the ring connected to the column is subjected to more stress as compared to the remaining half. The reason for this is as the ring acts as cantilever beam so the maximum stress produced is near to the fixed point. 


\section{International Advanced Research Journal in Science, Engineering and Technology}

Vol. 8, Issue 6, June 2021

DOI: $10.17148 /$ IARJSET.2021.8602

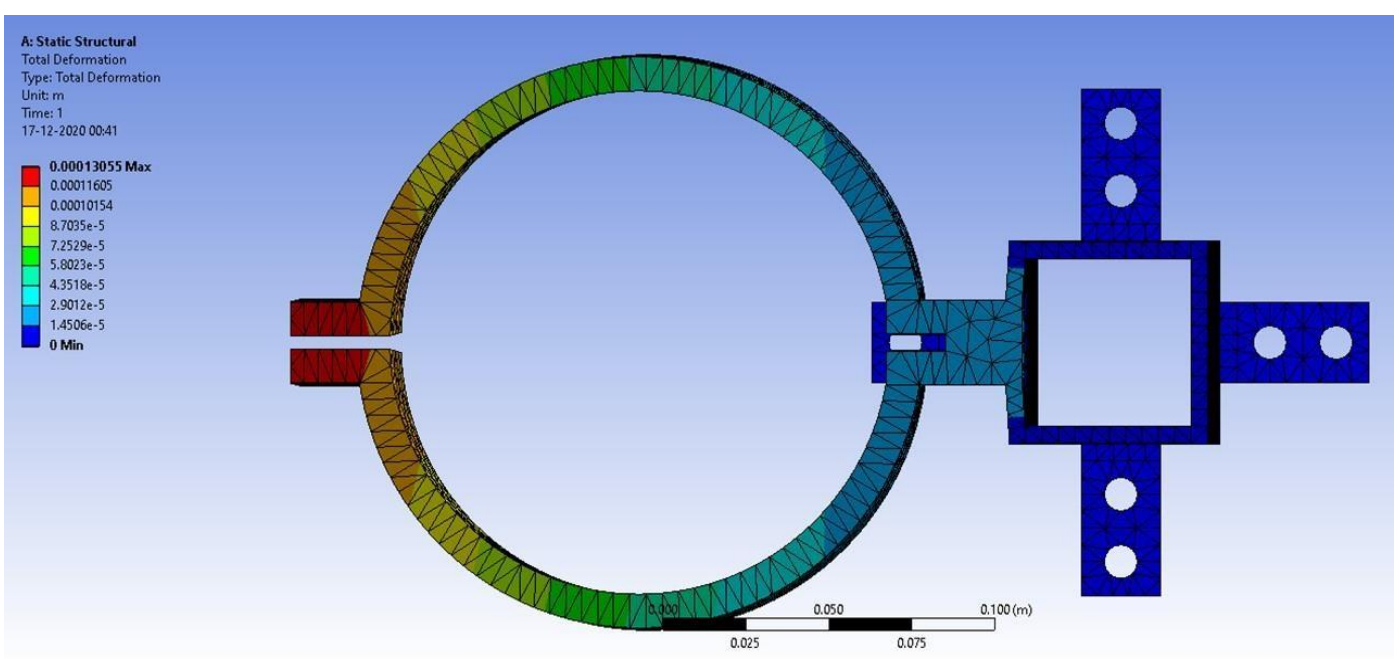

Fig 7 Deformation in Stand

As it can be seen in the Fig 7 the maximum deformation is observed at bolting point and the maximum deformation in the body is observed to be $0.13 \mathrm{~mm}$. The results obtained from analysis are within the acceptable limits suggested by industry.

\section{CONCLuSion}

The project work was carried out for making the process automatic by incorporating PLC, sensors, and actuators to work as effectively as possible. This project makes an optimization in the cycle time of the magnetic particle inspection process. The solution preparation system was successfully designed and automated. On successful implementation of TSS sensor in the solution tank, the time for checking solution concentration is reduced from $30 \mathrm{~min}$ to $2-5$ sec. By automation of the coil movement and spraying system, the cycle time of the process will be reduced by $47.5 \%$. The hopper was successfully designed for the storage of powder and to deliver powder at a velocity of $0.04 \mathrm{~m} / \mathrm{s}$ and at a pressure of $137.3 \mathrm{~Pa}$. The stand was designed to sustain the hopper load the maximum stress produced is $12.7 \mathrm{~Pa}$ and the maximum deformation is $0.13 \mathrm{~mm}$ which are within the specified limits. The integration and working of sensors and actuators in the system for performance evaluation are validated by PLC programming. The system automation has reduced human intervention in the entire process

\section{REFERENCES}

[1]. SlavisaAleksic, "A survey on Optical Technology for IOT, Smart Industry, and Smart Infrastructures”, Journal of Sensor and Actuator Networks, $2019,8,47$

[2]. Vinod Kulathumani and Bryan Lemon, "Sufficiency of Local Feedback for Sensor- Actuator Network based Control Systems with Distance Sensitivity Properties", Journal of Sensor and Actuator Networks ,2013, ISSN 2224-2708

[3]. ReinhardLangmann and Michael Stiller, "The PLC as a Smart Services in Industry 4.0 Production Systems", Journal of Applied Sciences, 2019,

[4]. HweeSann Lim, MohdZurr Mat Jafri, Khiruddin Abdullah, Sami GumanDaraigan, "A Sensitive Suspended sediment Sensor for the detection of TotalSuspended Solids(TSS)", OpticaApplicata, Vol. XLI, No. 3, 2011

[5]. Luis I. Minchala ,Jonnathan Peralta, Paul Mata-Quevedo and Jaime Rojas, "AnApproach to Industrial Automation based on Low-cost Embedded Platforms andOpen Software", Journal of Applied Science, 2020, 10, 4696S

[6]. Martin Obermeier, Daniel Schutz, Birgit Vogel-Heuser, "Evaluation of a NewlyDeveloped Model-Driven PLC Programming Approach for Machine and PlantAutomation", IEEE International Conference on Systems, Man and Cybernetics,2012

[7]. Yang Yu, Jingli Wang, Wei Liu, Chenxi Li, LU Zhao, Hao Fu, "Design of theControl System of Automatic Picking and Conveying Line based on PLC", IEEEInternational Conference on Robotics and Automation Engineering", 2017

[8]. KamilZidek, Jan Pitel, Milan Adamek, Peter Lanzorik and Alexander Hosovsky, "Digital Twin of Experimental Smart Manufacturing Assembly for Industry 4.0Concept", Sustainability, 2020, 12, 3658

[9]. Muhammad Awai, Syed Zulqadar Hassan, Tariq Kamal , Amir Zahoor ,Muhammad Abbas Khan , Muhammad TanveerRiaz "Control System forSpinning Machine Induction Motor using PLC”, July 2019, IEEE Spectr., vol.30, pp. 43-60

[10] Baumer, Ultrasonic distance measuring sensors (Article number: 11200623),U300.D50-DPMJ.72N 